\title{
Portal da Capes: contribuições para uma epistemologia crítica em pesquisa social
}

\section{Portal of Capes: contributions to a critical epistemology in social research}

\section{Portal Capes: contribuciones para una epistemología crítica en investigación social.}

Rosana Célia da Silva Carvalho, especialista em Metodologia da Pesquisa Científica pela Universidade do Estado do Pará (Uepa). Endereço: Rua Diogo Moia, 1921- Fátima. CEP: 66060-140-Belém, PA. Telefone: (91) 9116-9384. E-mail: rosanacscarvalho@gmail. com.

Rejane do Socorro da Silva Carvalho, mestra em Educação pela Universidade de Brasília (UnB). Endereço: Rua Diogo Moia, 1921 Fátima. CEP: 66060-140 - Belém, PA. Telefone: (91) 8729-5214. E-mail: carvalhorejann@yahoo.com.br.

\section{Resumo}

Aborda-se o Portal de Periódicos da Capes e sua relação com as pesquisas sociais engajadas em epistemologias críticas, objetivando analisá-lo como um veículo de informações para as pesquisas alinhadas à concepção materialista histórica diante da expansão das bibliotecas digitais e pela importância da contraposição às adversidades do sistema capitalista. À luz da concepção materialista histórica, empregou-se na metodologia: o método lógico-dialético; o método de procedimento comparativo; a coleta de dados por leitura analítica; a sistematização por fichamento analítico; e a análise de dados mediante análise crítica. As considerações finais são no sentido de que o Portal de Periódicos da Capes potencializa informações úteis para as pesquisas engajadas em epistemologias críticas, mas é necessária a busca de aprimoramento 
constante sobre o aspecto operacional do portal, para que ele seja eficaz sobre as pesquisas.

Palavras-chave: Portal. Digital. Periódicos. Capes. Epistemologia. Dialética.

\section{Abstract}

This article is about the Capes Portal of Periodicals and its link to social investigations related to critical epistemology, with the objective of analyzing the Portal as a vehicle of information for research aligned with the historic materialistic conception, considering the expansion of digital libraries and the importance of opposing the adversities of the capitalist system. In light of the historical materialistic conception, the methodology that was utilized involved a logical-dialectical approach, comparative procedures, data collection through analytical reading, the systematization of ideas, and critical analysis. The final considerations of the article indicate that the Capes Portal of Journals potentiates useful information for investigations related to critical epistemology, but it is necessary to seek constant improvement in the operational aspects of the portal in order for it to have a significant impact on research.

Keywords: Portal. Digital. Periodicals. Capes. Epistemology. Dialectic.

\section{Resumen}

Se aborda el Portal de Periódicos de la CAPES y su relación con las investigaciones sociales volcadas hacia epistemologías críticas, objetivando analizarlo como un vehículo de informaciones para las investigaciones vinculadas a la concepción materialista histórica ante la expansión de las bibliotecas digitales y por la importancia de la contraposición a las adversidades del sistema capitalista. A la luz de la concepción materialista histórica, se empleó en la metodología: el método lógico dialéctico; el método de procedimiento comparativo; la recolección de datos por lectura analítica; la sistematización por 
fichaje analítico; y el análisis de datos mediante análisis crítico. Las consideraciones finales muestran que el Portal de Periódicos de la CAPES potencializa informaciones útiles para las investigaciones volcadas hacia epistemologías críticas pero que es necesaria la búsqueda del perfeccionamiento constante sobre el aspecto operacional del portal, para que el mismo sea eficaz para las investigaciones.

Palabras clave: Portal. Digital. Periódicos. CAPES. Epistemología. Dialéctica.

\section{Introdução}

O modelo capitalista atual vem sendo garantido pelo poder de autorregulação do mercado, baseado no pensamento neoliberal, segundo o qual o Estado e as instituições sociais, econômicas e políticas devem preservar o seu pleno funcionamento, tendo repercussão nos setores do Estado, das instituições e, inclusive, das universidades.

Desse sistema, advêm contradições provenientes dos efeitos do sistema capitalista e do mundo globalizado, que repercutem sobre os países menos desenvolvidos, exigindo cada vez mais que sejam empenhados esforços dos cientistas no sentido de encontrar propostas para contrapor essa realidade.

A atenção para a informação digital se dá diante da percepção de que as bibliotecas virtuais vêm representando uma realidade em expansão por reflexo do avanço tecnológico mundial e do sistema produtivo contemporâneo.

Este artigo apresenta como importância evidenciar o Portal da Coordenação de Aperfeiçoamento de Pessoal de Nível Superior (Capes) como um espaço relevante de compartilhamento de ideias entre estudiosos das mais diversas áreas do conhecimento.

A importância do Portal da Capes se traduz em permitir o acesso a estudos e experiências sobre problemas atuais vinculados aos fenômenos produzidos pela globalização, já que essas possibilidades 
representam uma alternativa para potencializar uma reflexão ativa sobre as desigualdades existentes em decorrência do modelo econômico, valorizando a dialética tanto no aspecto epistemológico da concepção materialista histórica quanto no aspecto da utilidade do método dialético proveniente dessa corrente filosófica, especialmente, para a metodologia da pesquisa social, à medida que se volta para a dinâmica das relações concretas.

Temos a expectativa de contribuir de alguma forma, ainda que sem a pretensão de esgotar o assunto, para o estudo da informação digital e sobre a sua contribuição para as pesquisas sociais, com o objetivo de analisar o Portal da Capes, no bojo das bibliotecas virtuais, como um veículo de informações digitais voltadas para a reflexão sobre a importância das pesquisas científicas engajadas na linha de pensamento materialista histórica, constituindo um desafio pertinente a toda comunidade científica, estando estruturado em dois capítulos principais.

A seguir, apresenta-se o referencial teórico do estudo, abordando o pensamento de Marx acerca do materialismo histórico e a lógica dialética; posteriormente, trata-se da relação concebida entre o Portal da Capes e a sua importância para a pesquisa social.

\section{Dialogando com a teoria: materialismo histórico e lógica dialética}

Segundo Foulquié (1978), Marx reconheceu a dialética como a ciência das leis gerais do movimento, que tem início no mundo material e não no espírito, reinterpretando a dialética hegeliana, permitindo aferir-se que a dialética pode ser concebida como uma lógica, mas não uma lógica do espírito, e sim uma maneira de raciocinar o movimento do mundo concreto, tratando-se de uma lógica sobre a dinâmica do mundo concreto.

Segundo Chauí (1997), a filosofia hegeliana havia reunido lógica e dialética quando Hegel concebeu a dialética como a lógica do movimento do espírito, que é quando ele se manifesta como natureza e cultura, retornando a si como autoconhecimento de si mesmo. 
Um modo de compreender a dialética de Hegel, segundo Foulquié (1978), é compreender que o mundo e o espírito constituem princípios distintos, mas se relacionam por dependência mútua. O mundo é um meio de exteriorização para a ideia absoluta e a ideia absoluta toma consciência de si mesma graças ao mundo, quando nele se dispersa: primeiro, na forma de um espírito individual (por uma pessoa) e, depois, na forma de um espírito coletivo (por um grupo de pessoas). A ideia se exterioriza e permite a sua própria consciência por meio do mundo, que se apresenta em um plano secundário, sendo a ideia o princípio de tudo de que se toma consciência no mundo.

Para Hegel (apud Foulquié, 1978), a contradição é o que determina o desenvolvimento das ideias e das coisas. A ideia vai desenvolver-se por meio de uma luta de forças contrárias, identidade e contradição. Essa ideia de contradição vai ser exteriorizada pelo mundo e então passaremos a tomar consciência das contradições existentes no mundo material, o qual, somente a partir dessas contradições, também poderá evoluir, sendo a dialética a fusão dos contrários.

A ideia comporta ao mesmo tempo identidade e contradição, assim como o mundo, por meio do qual a ideia se exterioriza, quando nele se dispersa e permite a consciência das coisas. A identidade e a contradição, na concepção hegeliana, afloram primeiro na ideia e depois no mundo material.

Para Hegel (apud Foulquié, 1978) é a oposição entre os contrários na ideia e depois na matéria que garante o movimento e a evolução das coisas, pois se a identidade não se seguisse da contradição a ideia não se desenvolveria e as coisas ficariam estagnadas. A ideia se desenvolve pela contradição e se exterioriza pelo mundo, a partir do que toma consciência das contradições na matéria.

Segundo Foulquié (1978), Hegel, após aprofundar as filosofias anteriores, concebeu a dialética como a fusão dos contrários na ideia e na matéria, definindo a dialética como a fusão dos contrários, identificando o que chamou de afirmação, negação e negação da negação, ou seja, a existência do sistema tese-antítese-síntese, em que a negação da 
negação conservará tanto a afirmação quanto a negação, em uma fusão de contrários.

A dialética hegeliana não se opõe à dialética antiga baseada na contradição; ao contrário, nela se inspira. Na dialética antiga, a afirmação é o começo, o qual é seguido por uma negação que não põe fim à discussão. Para Hegel, a síntese ocorre ainda que implicitamente, e, especialmente, aflora na ideia quando se discute consigo próprio sobre pontos de vista contraditórios.

Hegel demonstrou o processo dialético por meio de um exemplo em função do ser: o ser é - o ser não é = o ser é desvir, concebendo que a síntese ultrapassa a contradição, conservando no seu interior tanto a afirmação quanto a negação (HEGEL, 1874 apud FOULQUIÉ, 1978).

A síntese não é definitiva; suscita sempre uma negação e uma nova síntese, indefinidamente. Trata-se de um processo incessante, que ocorre no plano da ideia e depois no plano da realidade, inclusive, sobre as coisas.

Enquanto Hegel concebeu um processo incessante em função do ser, da negação e da negação da negação, Marx acrescentou a essa ideia sua concepção filosófica materialista sobre esse processo. Nesse sentido, o materialista histórico de Marx constitui uma concepção sobre a história, segundo a qual as transformações ocorridas ao longo da história são impulsionadas pelas condições econômicas e materiais, e o materialismo dialético marxiano consiste em um raciocínio oposto à dialética idealista de Hegel, ao afirmar que a realidade material existe independentemente da consciência humana.

Pela concepção materialista histórica, as transformações históricas são fruto das contradições e da luta de classes. Tais transformações sofrem influência das condições econômicas dessas classes dentro do modelo produtivo vigente.

A dialética de Marx foi concebida como a lógica do movimento do mundo material, possibilitando a crítica sobre a realidade por diversos 
aspectos, contribuindo para a atitude crítica e ativa do indivíduo em relação à sua realidade.

Para Marx, não são as ideias que determinam as transformações; as ideias são dependentes das condições econômicas e materiais. As contradições na mente nascem a partir das contradições que ocorrem na realidade, ou seja, é no mundo que antes as contradições ocorrem e não no pensamento. Diversas condições concorrem para as transformações históricas, tais como as políticas, ideológicas etc., mas as condições econômicas têm predomínio, constituindo a base da qual dependem as superestruturas.

Marx influiu para evidenciar os aspectos de uma dialética capaz também de influenciar o indivíduo a pensar sobre o mundo concreto de uma maneira crítica, auxiliando-o diante das situações violadoras de direitos cometidas por arbitrariedades de agentes alocados na estrutura superior do modelo vigente na sociedade.

Segundo Boyle (2006), a burguesia emergiu das ruínas da sociedade feudal, não passando de uma superposição das formas medievais de poder. Nas suas altas estruturas, permaneceram alocados agentes de práticas inerentes ao regime absolutista.

Dentro do modelo capitalista, quantas arbitrariedades não foram cometidas para a garantia do sistema, quer por motivo de convicção filosófica, quer por motivação política? Provas de tais fatos são, na maior parte das vezes, escamoteadas pelos agentes criminosos, sendo inúmeras as vítimas de abuso de poder, sendo engano pensar que os fatos são isolados dentro do sistema. Tais práticas persistem em órgãos e instituições por conta do poder de soberanos ou pelo poder conferidos a indivíduos que estão ali para manter ou se prestar a manter as práticas centenárias de abuso de poder, havendo, ainda, a proteção do corporativismo de classe e o medo por grande parte das vítimas, o que contribui para que os criminosos não sejam expurgados com facilidade.

A lógica dialética da realidade concreta constitui um raciocínio crítico de auxílio à pessoa, ao orientá-la dentro da sistemática capitalista, 
no sentido de que precisa estar consciente do porquê das coisas ocorrem dessa ou daquela maneira.

Essa mesma lógica contribui para a percepção de que o modelo capitalista procura prevenir-se contra qualquer leve roçar contra sua estrutura. Um olhar analógico sobre a lógica dialética materialista no curso da história é capaz de demonstrar isso.

Do mesmo modo que as velhas potências da Europa procuraram “exorcizar” o comunismo, menosprezando-o, de certo, por considerarem sua significância, de igual modo, quaisquer possibilidades de alteração no sistema, mesmo ínfimas, precisam ser "exorcizadas", para a garantia de que nenhuma propensa alteração qualitativa possa remotamente vir a ameaçá-lo futuramente, bem como todo aquele que possa ameaçar, ainda que remotamente, a estrutura do sistema precisará ser destruído, pelo que muitas vezes assistimos a perseguições e abusos contra o indivíduo.

Segundo a lógica materialista, o sistema está baseado no patrimônio à conta da exploração das forças produtivas, por isso os agentes do topo da pirâmide do sistema não desconsideram o princípio dialético da possibilidade de transformação qualitativa.

Segundo a dialética concebida por Marx, os conflitos são fruto da realidade concreta, não brotam do espírito como dizia Hegel, pois a concepção marxiana é a de que as contradições surgem na matéria e não na ideia. E, de fato, o que se passa na ideia é apenas reflexo do mundo e não o contrário, pois se temos contradições, por exemplo, sobre algo da realidade, quer seja da natureza, quer seja da cultura, como poderiam essas contradições brotar automaticamente do espírito sem que antes o espírito tivesse deparado com elas?

Aos que se empenham na lógica dialética materialista, compreende-se como primordial a transformação social pelo agir. Na ciência, o investigador dessa vertente deve encontrar-se presente ativamente na investigação, não se colocando como captador inerte dos dados empíricos. 
Pela dialética marxiana, a questão econômica é o que está por trás dos conflitos na sociedade, envolvendo diretamente a vida concreta das pessoas e os conflitos, influenciando a luta por transformações no curso da história. Trata-se de uma reflexão crítica sobre a realidade concreta e sobre a forma como ela pode ser alterada, segundo uma lógica pertinente à realidade, percebendo-se aqui o aspecto materialista dessa concepção de mundo, segundo a qual o mundo se movimenta por conflitos fundados na questão econômica e na luta de classes.

A utilidade da concepção materialista histórica está tanto no aspecto epistemológico, com base no critério da historicidade e da totalidade, quanto no aspecto da utilidade do método dialético proveniente dessa corrente filosófica, especialmente, para a metodologia da pesquisa em ciência social, à medida que se volta para a dinâmica da realidade. Se não é desejável que o indivíduo não reflita acerca das contradições por ele assistidas dentro da sua realidade, é menos desejável do pesquisador que aborde a realidade social de um ponto de vista estanque, sem estabelecer as diversas relações que implicam e envolvem o objeto pesquisado dentro do contexto em que está inserido.

No Brasil, segundo Melo (2009), as abordagens brasileiras sobre a dialética reproduziram as vertentes européias hegeliana e marxiana. Para a autora, prevaleceu a vertente hegeliana dos fins da década de 1950 até o início dos anos 1960 e depois a vertente marxiana, principalmente após a revolução de 1917 na Rússia, um grande acontecimento para o movimento comunista internacional, sendo Lênin e Trotsky os representantes mais credenciados da dialética marxista.

Para Melo (2009), entre as três vertentes teóricas do marxismo que mais influenciaram o pensamento dialético brasileiro, a primeira foi derivada das obras de Lênin, que foi seguida pelo Partido Comunista do Brasil (PCB) até agosto de 1961, quando sua denominação foi modificada para Partido Comunista Brasileiro, tendo como principais teóricos Werneck Sodré, Guimarães Passos e Carlos Prestes, que defenderam que, para alcançar o socialismo, seria necessário implantar-se antes a revolução democrático-burguesa, pois fortaleceria a classe proletariada. Para os membros do PCB, o proletariado poderia se aliar à burguesia 
nacional para efetivar essa revolução, mas não poderiam deixar-se dominar por ela, pois em vista de uma leve suspeita de atraiçoamento pela burguesia o proletariado deveria combatê-la, devendo o proletariado conservar seu caráter independente do movimento burguês.

No entanto, ao longo dos anos 1960, surgem no próprio PCB sérias divergências, principalmente quanto aos métodos de luta e prática política, culminando em numerosas dissidências, dessas divergências surgindo o Partido Comunista do Brasil (PC do B); a Aliança Libertadora Nacional (ALN); a Vanguarda Popular Revolucionária (VPR); e o Movimento Revolucionário 8 de Outubro (MR8), que criticava a luta pacifista e legalista, fazendo apelo à luta armada, de acordo com as posições de Fidel Castro, Che Guevara, Régis Debray e Mao Tsé-Tung.

A segunda vertente, derivada das ideias de Trotsky, contribuiu para as teses da IV Internacional e foi representada por várias organizações políticas e pensadores; e, posteriormente, a terceira vertente foi baseada no pensamento do líder da Revolução Chinesa Mao Tsé-Tung, pensamento que se aproxima das ideias de Trotsky, diferentes quanto às questões políticas específicas.

\section{O Portal da Capes e a pesquisa social}

Ao considerarmos o materialismo histórico reflexo de uma epistemologia crítica, que concebe os conflitos como fruto da realidade objetiva, repleta de contradições e influenciada por fatores econômicos, a contestação das situações sociais opressivas produzidas pelo sistema atual se dá mediante uma conduta ativa perante essas contradições, com a consciência de que o cientista precisa ser compreendido como um sujeito ativo sobre a realidade estudada. O modelo capitalista, que se contradiz ao explorar o ser humano, confronta-se a partir de uma crítica social, segundo um raciocínio dialético ativo contra o modelo fomentador da desigualdade.

Nesse sentido, o reconhecimento da dialética materialista como a ciência das leis gerais do movimento tanto do mundo exterior 
como do pensamento humano, tendo início esse movimento no mundo material e não no espírito, implica também o seu emprego como um método lógico adequado à pesquisa social, à medida que, à luz da concepção materialista histórica, a dialética pode ser tomada como uma lógica crítica sobre a dinâmica do mundo concreto, bem como uma análise crítica sobre essa dinâmica, na forma de um raciocínio sobre as contradições da realidade, que necessitam ser superadas.

Admitindo-se, assim, a divulgação e a promoção do acesso à informação científica digital e o intercâmbio entre os pesquisadores por meio do uso do Portal de Periódicos da Capes constitui um desafio à Capes e às universidades brasileiras.

Segundo Zang et al. (2000 apud OHIRA; PRADO, 2002), o termo digital quer dizer uma forma de apresentação de acervo digitalizada, ou seja, o acervo digital pode assumir diferentes formas de mídia, tais como disquete, disco rígido, fita, disco compacto etc.

A título de exemplo, para Macedo e Modesto (1999 apud OHIRA; PRADO, 2002), para constituir uma biblioteca digital, os materiais convencionais, como impressos e livros, devem ser digitalizados, isto é, precisam ser convertidos para o formato digital.

O Portal da Capes, por um aspecto objetivo, constitui um meio que permite a busca de textos digitalizados de diversos autores nacionais e internacionais e o compartilhamento de informações no auxílio de estudos e trabalhos científicos.

Podemos considerar que o sistema do Portal da Capes, em linhas gerais, dá acesso a acervos nacionais e internacionais, que estão sob a forma digital, o que, em uma perspectiva prática, constitui um importante recurso viabilizador de informação, desde que bem aproveitado.

Falando sobre uma perspectiva subjetiva, o Portal da Capes pode funcionar como um canal de diálogo e como uma nova alternativa para o tratamento dialético das abordagens científicas dos fenômenos produzidos no contexto do mundo globalizado. 
A partir do momento em que se abre um canal de acesso a estudos e experiências sobre questões atuais, compartilhamento e troca de ideias sobre problemáticas gerais no mundo contemporâneo, com acesso a ideias e opiniões de autores das mais diversas regiões do mundo sobre questões comuns do nosso tempo, isso não deixa de representar uma importante alternativa para viabilizar informações científicas.

Podemos perceber atualmente uma expansão de novas formas de dominação ideológica e imperialista pelas grandes potências mundiais. No passado, assistimos a formas aparentemente diversas de dominação por esses países, pois naquela época o que se via era um imperialismo voltado para a expansão de fronteiras. Nos dois momentos, no entanto, podemos observar semelhanças na tendência de tentativa de superposição de uma potência sobre as demais, mas pouco diferente do que existe hoje, no que se refere ao avanço da globalização sobre as fronteiras mundiais.

Segundo Hardit e Negri (2001), está acabada a era dos grandes conflitos, da história das guerras imperialistas, interimperialistas e antimperialistas, no sentido de que agora o poder soberano expande progressivamente suas fronteiras para envolver todo o globo, como seu domínio próprio, introduzindo uma nova era, mas de conflitos internos, sendo cada vez mais difícil para os ideólogos dos Estados Unidos citarem um único e unificado inimigo, havendo inimigos menores e esquivos em toda parte. Assim, a realização do mercado mundial constituiria o ponto de chegada da tendência a incluir mais e mais na esfera de dominação do mercado capitalista, em que o mercado mundial seria um modelo para compreender a sua soberania imperial.

Nessa linha de raciocínio, a globalização, por certo aspecto, representa um risco para as culturas e expressões dos países menos desenvolvidos, já que a comunicação mundial estabelecida entre as pessoas não assegura as diversas identidades e expressões culturais dos grupos periféricos que se encontram espalhados no mundo. Temos que nos preocupar com as generalizações produzidas pela globalização, pelo risco de prejuízo das especificidades. Há sempre 
o risco de dominação cultural pela expansão de uma cultura sobre as outras. Não podemos ignorar as indústrias culturais; vemos, por exemplo, o poder que tem a indústria cinematográfica dos Estados Unidos, a indústria da música e outras, tudo fazendo parte do quadro real que deve ser objeto de reflexão pela comunidade científica. Nunca se pode perder de vista que o capitalismo é globalizante, tendendo a uma homogeneização na sociedade que contradiz a questão das diferenças. É nessas circunstâncias, inclusive, que os movimentos de afirmação de identidades raciais, sexuais, locais etc. procuram estratégias para fazer frente a uma possível dominação de identidades.

A respeito da tendência de homogeneização refletida pela globalização sobre os países menos desenvolvidos, como é o caso do Brasil, os cientistas brasileiros estão inseridos no contexto do dinamismo do mundo globalizado, que influi para a expansão de uma dominação ideológica como uma versão contemporânea da expansão imperialista assistida no passado, refletindo uma interação mundial voltada para a expansão de novas formas de dominação ideológica e imperialista.

A Capes vem se empenhando em promover a informação digital, o que constitui, em si, um grande desafio, pois se refere a tornar o portal um veículo concreto de informações no auxílio das pesquisas científicas, com o efeito prático de multiplicar a atitude de utilizar o portal no sentido de atingir a satisfação do pesquisador em compreender o objeto de estudo, bem como em contribuir para a realidade em que o objeto está envolvido na prática das relações cotidianas.

Nessa linha de raciocínio, o desafio da Capes e da utilização do seu portal de periódicos representa um desafio que esbarra também na necessidade de mais engajamento por parte dos cientistas. Por analogia, podemos citar uma situação não muito distante desse desafio, por exemplo, no campo dos programas de pós-graduação no Brasil podemos perceber a necessidade de mudança de hábitos na forma de ingresso nos programas de pós-graduação, pois nem sempre se prioriza o aspecto da maturidade epistemológica apresentada pelo candidato, situação essa que, em tese, acarreta um quadro potencial de futuros pesquisadores muito menos críticos do que se poderia esperar. 
Convivemos com novas formas de dominação ideológica, trazendo um impacto também para as universidades; não só um impacto sobre a importância das expressões dos grupos locais, mas também sobre a necessidade de que dentro de seus programas sejam considerados princípios filosóficos contrapostos ao paradigma dominante, ao crermos que a relação dialética traz um necessário contrapeso para a tendência à homogeneidade na era global.

Seria necessário que se analisasse o contexto histórico do avanço ideológico das fronteiras e a influência do modelo econômico sobre as relações sociais, considerando que os fenômenos contemporâneos encontram-se inseridos em um universo em progressiva expansão, afigurando-se no contexto contemporâneo como conflitos internos, não se podendo analisá-los sem os relacionar com seu passado e com o sistema como um todo em que estão inseridos.

Nesse aspecto, Foulquié (1978) entende que teria o método dialético introduzido uma nova forma de olhar para o fenômeno, pois ele estaria sujeito às ações recíprocas existentes entre as diversas partes de um todo, estando o universo em puro movimento e em constante transformação, jamais podendo ser analisado isoladamente.

Nesse sentido, o uso de um portal digital de pesquisas representa uma alternativa coerente para tratar de pesquisas científicas sobre problemas sociais ligados à dinâmica do mundo globalizado, havendo a constatação da relação existente entre os problemas concretos e as tendências na esfera mundial.

No mundo do trabalho, se, por um lado, a forma de trabalho assalariada vem sendo substituída pelas formas de trabalho precárias do modelo produtivo, entre essas novas formas de contrato, os contratos de curta duração, com o avanço dos modelos de trabalho sob a forma das terceirizações, assim como outros fenômenos do mundo globalizado, por outro lado, a sociedade do conhecimento se faz refletir na forma de exigências cada vez mais fortes de qualificação, de eficiência, de versatilidades e de capacidades diferenciadas dos indivíduos. 
No mesmo sentido, os professores têm diante de si o avanço das tecnologias da informação e da comunicação (TICs) e o desafio das novas relações pedagógicas, ao mesmo passo que o modelo capitalista faz exigência por uma pronta formação e com alto nível de qualidade, ainda com o desafio de fazer valer a educação não simplesmente como um veículo de formação de mão-de-obra servil aos paradigmas econômicos oprimentes no mundo do trabalho.

Por outro aspecto, sem perder de vista o campo do Direito, lembramos que existem, ainda, as contradições e arbitrariedades provenientes do modelo capitalista que afetam diretamente os direitos fundamentais do indivíduo, na forma de manifestações típicas das sociedades de classe, tais como arbitrariedades e crimes.

Todo esse quadro traz para as universidades brasileiras, portanto, um impacto sobre a importância de promover e divulgar o acesso à informação na era global. Por intermédio do Portal da Capes, abre-se acesso a uma maior gama de informações digitais, assim como se promove o intercâmbio de ideias voltadas para contrapor a dinâmica do mundo globalizado, tão debatida no meio científico e que compete, em última análise, com seus programas educacionais.

Além disso, é preciso que se dedique a necessária atenção para o aspecto objetivo do portal, a fim de que ele possa ser realmente utilizado pela comunidade como um canal de busca, efetivamente, para a obtenção de informações e o compartilhamento de estudos no auxílio dos trabalhos científicos.

Para Meirelles e Machado (2007), o Portal da Capes apresenta desempenho satisfatório, mas é recomendável, no aspecto da legibilidade, uma melhoria na interface com os usuários, apontando, à época da sua pesquisa, que 46\% dos respondentes consideravam o layout regular e 20\% ruim, considerando os indicadores não suficientemente adequados para uma boa legibilidade, à ocasião, para esse grupo de usuários.

Em se tratando do uso das bibliotecas digitais e do uso do Portal de Periódicos da Capes, as pesquisas existentes apontam fatores 
diferenciados quanto ao seu não uso, conforme pesquisas sobre o uso da biblioteca digital de periódicos da Capes entre as áreas do conhecimento.

Para Cunha e Cendón (2010), existem diferenças de comportamento entre pesquisadores de uma mesma área, considerando que variáveis intervenientes e fatores de motivação aparecem como barreiras e estímulos para o uso do portal, respectivamente, destacando que os comportamentos e as justificativas para o uso e não uso de periódicos pelos pesquisadores entrevistados apresentam grandes diferenças.

Considerando os fatores apontados nas pesquisas existentes, observamos como uma maneira eficiente para avaliar a funcionalidade do Portal de Periódicos da Capes a realização contínua de pesquisas sobre a interface com os usuários, com vistas à atualização constante das necessidades e dificuldades dos seus usuários, visando aprimorar o seu desempenho, pois, em geral, as pesquisas existentes apontam que o seu desempenho é relativamente satisfatório.

Pensamos que o Portal da Capes constitui, nesse sentido, um reforço às pesquisas científicas, facilitando o acesso à informação digital e permitindo o intercâmbio entre os pesquisadores por meio da rede mundial de computadores, tratando-se de um recurso inserido no contexto da difusão da internet em nível mundial, precisando ser utilizado na perspectiva das contribuições positivas do avanço tecnológico voltadas para a facilitação do trabalho de pesquisa, caso em que a tecnologia é utilizada no sentido da viabilização das pesquisas científicas, mas, sobretudo, precisando ser utilizada no sentido de contribuir para uma reflexão crítica sobre a pesquisa social.

\section{Considerações finais}

À luz da concepção materialista histórica, que desnuda a violação de direitos dentro do sistema capitalista, despertando a consciência crítica do violado para lutar em defesa de seus direitos, entendemos que as pesquisas científicas engajadas em epistemologias críticas têm 
grande importância para fazer frente às adversidades e à dominação ideológica presente no plano das grandes potências e da globalização.

Como um meio de acesso a estudos e de troca de ideias sobre o mundo atual e suas crises, o Portal da Capes potencializa um canal de compartilhamento de informações, constituindo um reforço para as pesquisas guiadas por epistemologias críticas dos fenômenos sociais.

As bibliotecas digitais, em que se incluem a da Capes e o Portal de Periódicos, refletem o avanço da globalização e da tecnologia, constituindo uma oportunidade de interação de estudos e ideias que se estendem em plano internacional, o que é útil para pesquisas científicas engajadas em epistemologias críticas do modelo produtivo, pelo intercâmbio de conhecimentos que favorecem, potencializando o questionamento das posturas de conformação ao modelo posto, no sentido de redefinir o papel do pesquisador à luz da análise histórica e de totalidade que precisa cercar os problemas abordados.

Mas para que a utilidade das bibliotecas virtuais seja um fato, no presente caso, em se tratando do Portal da Capes, é importante que se priorize o aspecto da eficiência operacional do portal, a fim de que seja utilizado efetivamente pelos pesquisadores para que tenha eficácia para as pesquisas em ciência social, sendo plenamente aproveitado.

Nesse sentido, faz-se recomendável a realização contínua de investigações sobre o Portal da Capes e sua interface com os seus usuários, considerando-se a importância de manter a atualização constante sobre o conhecimento das necessidades e dificuldades quanto ao aspecto operacional dos recursos que o portal oferece.

Recebido 29/09/2010

Aprovado 01/08/2011 


\section{Referências bibliográficas}

BOYLE, D. 0 manifesto comunista. Rio de Janeiro: Zahar, 2006.

CHAUII, M. Convite à filosofia. 6. ed. São Paulo: Ática, 1997.

CUNHA, A. A. L.; CENDÓN, B. V. Uso de bibliotecas digitais de periódicos: um estudo comparativo do uso do Portal de Periódicos da Capes entre áreas do conhecimento. Perspectivas em Ciência da Informação, Belo Horizonte, v. 15, n. 1, 2010. Disponivel em: <http:/ /www.scielo.br/scielo. php?pid=S1413-99362009000200017\&script=sci_arttext $>$. Acesso em: 28 set. 2010.

FOULQUIÉ, P. A dialéctica. 3. ed. [S.I.]: Publicações Europa-América, 1978.

HARDIT, M.; NEGRI, A. Império. Rio de Janeiro: Record, 2001.

HEGEL, 1874 apud FOULQUIÉ, P. A dialéctica. 3. ed. [S.I.]: Publicações Europa-América, 1978.

MACEDO, N. D. de; MODESTO, F., 1999 apud OHIRA, M. L. B.; PRADO, N. S. Bibliotecas virtuais e digitais: análise de artigos de periódicos brasileiros (1995/2000). Ciência da Informação, Brasília, v. 31, n. 1, 2002. Disponivel em: <http://www.scielo.br/scielo.php?pid=S0100$19652002000100007 \&$ script=sci_arttext\&tlng=es $>$. Acesso em: 28 set. 2010.

MEIRELLES, R. F.; MACHADO, R. das N. A funcionalidade e o desempenho do Portal de Periódicos da CAPES entre pesquisadores das áreas de Comunicação e Ciência da Informação da Universidade Federal da Bahia. Perspectivas em Ciência da Informação, Belo Horizonte, v. 12, n. 3, 2007. Disponivel em: <http:// www.scielo.br/scielo.php?pid=S141399362007000300005\&script=sci_arttext\&tlng=in>. Acesso em: 28 set. 2010. 
MELO, L. A concepção dialética na didática da formação de professores. In: ENCONTRO DE DIDÁTICA E PRÁTICA DE ENSINO, 3., 2009, Belém. Belém: Uepa, 2009.

ZANG et al., 2000 apud OHIRA, M. L. B.; PRADO, N. S. Bibliotecas virtuais e digitais: análise de artigos de periódicos brasileiros (1995/2000). Ciência da Informação, Brasília, v. 31, n. 1, 2002. Disponível em: <http:/ / www.scielo.br/scielo.php?pid=S0100-19652002000100007\&script=sci_ arttext\&tlng=es>. Acesso em: 28 set. 2010. 